Case Report

\title{
Applicability of Surveying Professional Practice in Land Use Planning for Community Land Conflict Extrication in Mbeya Rural Area
}

\author{
Ramadhani Said Tekka \\ Department of Built Environment Engineering (BEE), Mbeya University of Science and Technology, Mbeya, Tanzania
}

\section{Email address:}

ramsotekka@yahoo.co.uk

\section{To cite this article:}

Ramadhani Said Tekka. Applicability of Surveying Professional Practice in Land Use Planning for Community Land Conflict Extrication in Mbeya Rural Area. Journal of Civil, Construction and Environmental Engineering. Vol. 3, No. 1, 2018, pp. 5-9.

doi: $10.11648 /$ j.jccee.20180301.12

Received: December 22, 2017; Accepted: January 6, 2018; Published: January 19, 2018

\begin{abstract}
Land conflict has been noted to be an intervening phenomenon for quite longer as it has caused many misunderstanding, competition and violence between different society group as well as adjacent land owners. Different factors has been noted in different literatures related to land conflict like scarcity of resource (water, land, pasture), policies, politics on land decision matters, land law, irregularities on land allocation procedures etc. This study explains the applicability of surveying professional practice in land use planning for community land conflict extrication in Mbeya rural area. Three districts were randomly selected as a pilot survey area for the study. Land officer, land surveyor and planners were considered as important participants in land related issues as well as participating in land conflict extrication. The study revealed that poor procedure on land planning and demarcation, poor technical survey skills, poor adherence to survey practice as well as poor participation of surveyors from inception and or during base map and or town planning drawing preparation mostly results to poor and or incorrect drawing which would always be used by the planner for land use planning. However the use of inaccurate surveying equipment like a hand held Global positioning system (GPS) which has the accuracy of up to $\pm 3 \mathrm{~m}$ was noted to facilitate encroachment and hence the land conflict between neibour if not well and early settled. Nevertheless the applicability of the surveying professional practice was considered to resolve the problems. A well trained and experienced surveyor should be engaged during preliminary spatial data capture for base map and or town planning drawing preparation, a work which to-date at large is being done by the planner who in reality lacks the surveying professional practice in either using surveying equipment or data analysis something in turn leads to prolonged land conflict.
\end{abstract}

Keywords: Surveying, Land, Land Use Planning, Land Conflict

\section{Introduction}

Land as natural resources plays a significance role in social - economic development of any country. The demand for land coupled with the ensuing conflicts over its access and control in Tanzania's big cities, and towns has been strikingly rising time due to rapid urbanization which to a great extent attributed to rural-urban migration as slow growth in productive employment in labor intensive sector. [10] The proper land use planning and allocation would have to maximum used to minimize the land conflict in society of would if would have been done properly while attaining ethical and code of conduct. Land planners are emphasized to apply proper or to participate fully with surveyor in applying the proper surveying professional practice which in turn would serve to avoid land conflict resulted from poor land conflict as a result of land demarcated encroachment. The proper application of surveying professional practice and instruments during land use planning may assist to solve the problem amicably. 
Surveying-Surveying is an art and or a science of taking the measurement of the natural and manmade features available beneath or on the earth's surface and plotting those measurement obtained using a scale so as to produce a plan or a map. [1]

The main objectives of surveying is the preparation of plans and map of a particular intended area which can be used for different purpose including but not limited to boundary or land demarcation, road, railway, canals, tunnels alignment, transmission of power lines etc.

The information or data obtained and recorded on site during surveying can be represented as numerical data $\mathrm{s}$ well as graphical data through which maps can be produced.

The accuracy of the output (map) needs to be dictated at first during reconnaissance stage and enough checks must be applied to the field work as well as during the preparation of the plans so as to provide an acceptable accuracy of the result.

Land is one among the important parameters and a major means of production where also all living creatures depend for their living. More important, land is a life supporting part where most of the activities like agriculture, oil, wildlife, mining, forestation, national park, livestock keeping, residence and many more depend. All these resources generally prove the UN-HABITAT (2012-IX) statement that "Everyone has a relationship to land" [2]

In the most popular scholar article famously known as Issa shivji's land report (1994) highlighted the stronger accent on the importance of smallholder farmers as said in [3]:

"For the smallholder in Tanzania and elsewhere, land is much more than simply a factor in economic production. It is his/her lifeline. One would risk loss of one's land if there was a potential alternative means of livelihood, for example on the labor market. That hardly exists. Therefore, in the rural areas, loss of land means virtually marginalization and eventually destitution".

As described in [4], Land is primarily a basic aspect that represents a core value in African society. Most African people if not all are psychologically and expressively attached to their land which represents an imperative foundation of their identity and is typically seen in a holistic perspective (Donge and Pherani, 1999: 50)

In many African traditional societies, access to land had been characterized as relatively democratic; to date Land is increasingly becoming a source of conflict in sub-Saharan Africa countries. It has been shown that the local land conflict has erupted into large-scale civil conflict and political movements' at large (Ande and plateau, 1998, Daudelin, 2002). [5].

Different fundamental factors, such as climatic change, population pressure, agricultural commercialization, agropastoralist activities, urbanization as well as other variable factors in most areas in Africa, have to a great extent contributed to the increasing hardship life as a result of difficulties in accessing water and land availability for grazing has automatically resulted to concern on food insecurity, increasingly of poverty occurrence, destruction of social and economical infrastructure as well as land conflicts and hence that would turn into widespread of civil wars in the affected society thereby becoming a threat to the national security. This has been noted in [5]. (Andre and Plateau, 1998; Deininger and Castagnini, 2006)

Land Use Planning- Is the process which involves lands evaluation and assessment so as to become a basis for the decisions, involving land disposition and utilization. It also involves the studies related to environmental effects of land use and its effects to the particular community surrounding [9].

As of [9], Land use planning does not only consider production but also land functions such as protected areas, land recreation, infrastructure development, waste disposal sides, area for regenerating ground water, buffer zones for traffic noise pollution etc.

Generally land use planning involves the creation of the fundamentals needed so as to achieve the sustainable type of land use which is socially enviable, environmentally friendly and economically sound.

Land conflict- Land Conflict has been noted to be on e of the overwhelming phenomenon in many parts of the world. The conflict always arises when two or more groups believe that their interests are incompatible when the community mechanisms with their believing in organization for supervision, managing and resolving conflict fail to operate properly and hence giving way to violence.

The situation becomes worse if other factors like fragile political systems as well $\mathrm{s}$ the social divisive relations are drawn in to the cycles of conflict and hence violence [7].

Despite of many studies done on land conflict issues; it has been so difficult to determine the frequency occurrence of the land conflict on a particular area. While considering a large part of land in Mbeya rural areas squatter; small effort has been taken to increase the availability of a surveyed land. This has been due to unavailability of enough funds, little available surveying equipment, and very few professional surveyors to undertake the exercise.

However the small parts surveyed has also shown to have so many land conflict as a result of encroachment that has been noted to be resulted from improper application of surveying professional practical though the entire process of planning to land demarcation.

Many studies on land conflict have been done and the conclusion derived on but the conflicts are still persisting. Many conflicts have been noted not only between agro-pastoralists and peasant but also between individual civil people within the society as a result of encroachments between different adjacent land owners. Also the boundary and inheritance as a form of conflicts has to a great extent happened for quite longer. This has been generally persisted because of poor or inaccurate land use planning and demarcation strategy, use of inaccurate surveying instrument like Hand Held Global Positioning System during planning and poor procedures during land use planning and allocation. Generally, lack of and poor professional surveying practice 
during land use planning to land demarcation to large extent has facilitated land conflict in Mbeya rural area.

\section{Methodology}

The methodologies used in data collection were divided into two categories, which are:

1. Preliminary investigation of the submitted customer files to the land planning officers claiming for land encroachment and hence land conflict between adjacent land neighbors.

2. Questionnaire. The closed ended questionnaire were prepared and distributed to land related officers including 8 land officers, 4 land surveyors as well as 10 planners from Mbeya rural, Mbarari, Kyela and Rungwe districts. The respondents were randomly selected to get their views in relation to their participation in land use planning, surveying and managements.

Presence of conflict, rate of conflict, use of inaccurate survey instrument during data collection for planning, poor technical survey skills, procedures used during planning, Participants in planning, adherence to surveying professional practice during planning and demarcation were the parameters used for the assessment and justification of the study.

\section{Data Analysis}

Data analysis was based on the nature and type of questions developed in questionnaire. The following was the equation used to determine the respondents.

$$
P=\frac{f}{\sum_{i}^{n} f} \times 100 \%
$$

Where $\mathrm{f}=$ Number of respondents to the particular case $\mathrm{P}=$ Percentage of respondents to the particular case

$\sum_{i}^{n} f=$ Total number of respondents participated in the research.

\section{Findings}

This part sought to describe briefly the result views from the respondents in relation to our study.

\subsection{Information of Respondents}

Table one below indicates the number of participants on this study who were professionals participating fully in the field of land. The respondent's age ranged from 24-49years. Basing on gender sensitivity only $27 \%$ of the respondents were female workers leaving many male to dominate in land related field. However $88 \%$ was a university graduate with more than four years working experience in the land related field. These indicate to have acquired appropriate information from the acquainted people on land related issues.
Table and figure 1 below refers. Study Participants

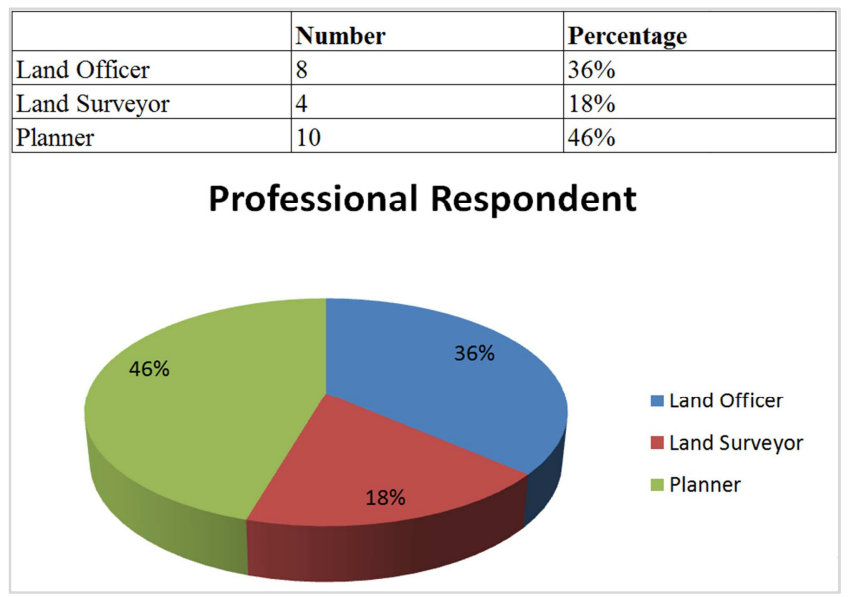

Figure 1. Participants of the study.

\subsection{Investigation on the Availability and the Factors Associated to Land Conflict}

The question were posed to respondents to verify if really there is overwhelming land conflict to the society. All respondents agreed to have faced with many challenges related with land conflicts throughout their entire working time. As noted from figure 2 below, some of the cases were reported and filed. This was identified during preliminary investigation. Despite of the data available, it is still difficult to predict the frequency of the land conflict occurrence.

Conflict Cases reported per year

\begin{tabular}{|c|c|c|c|c|c|}
\hline & \multirow{2}{*}{$\begin{array}{l}\text { Mbeya Rural } \\
23\end{array}$} & Rungwe & Mbarali & \multicolumn{2}{|c|}{ Kyela } \\
\hline 2013 & & 16 & 33 & \multicolumn{2}{|c|}{13} \\
\hline 2014 & 18 & 21 & 21 & \multicolumn{2}{|l|}{15} \\
\hline 2015 & 20 & 19 & 22 & \multicolumn{2}{|l|}{10} \\
\hline 2016 & 18 & 16 & 26 & \multicolumn{2}{|l|}{17} \\
\hline \multicolumn{6}{|c|}{ Land Conflict Cases for Three } \\
\hline 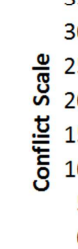 & 5 & & & & $\begin{array}{l}\square 2013 \\
\square 2014 \\
\square 2015 \\
\square 2016\end{array}$ \\
\hline & Mbeya Rural & $\begin{array}{l}\text { Rungwe } \\
\text { Distr }\end{array}$ & & & \\
\hline
\end{tabular}

Figure 2. Land conflict cases reported.

It was also observed that most of the land conflicts are associated with encroachment of the adjacent plots. This was due to inaccurate data always taken by inaccurate instruments used by the planner at the beginning when taking the data for preparation of the town planning drawings. It was 
emphasized to use surveyors in data collection instead of planner who have little knowledge on spatial data capture and processing.

However, as figure 3 shows, factors like poor technical survey knowledge, use of inaccurate survey instrument, and poor participation of surveyor during data collection for land use planning as well as non adherence to professional survey practice from inception to completion of planning process were noted to be the factors for land dispute arise.

Factors for Land Conflict

\begin{tabular}{|l|l|r|}
\hline Factors for Land Conflict & Factor Remark & $\begin{array}{l}\text { Percentage of } \\
\text { Respondents }\end{array}$ \\
\hline Use of Inaccurate instrument & A & 100 \\
\hline Poor technical survey skill & B & 93 \\
\hline Poor procedure in data collection & C & 56 \\
\hline Poor participation of surveyor & D & 91 \\
\hline Poor adherance of survey practice & E & 89 \\
\hline Few number of planner & F & 16 \\
\hline Insufficient fund for the work & G & 22 \\
\hline Lack of land law knowledge & H & 31 \\
\hline Presence of few professional surveyd I & 73 \\
\hline
\end{tabular}

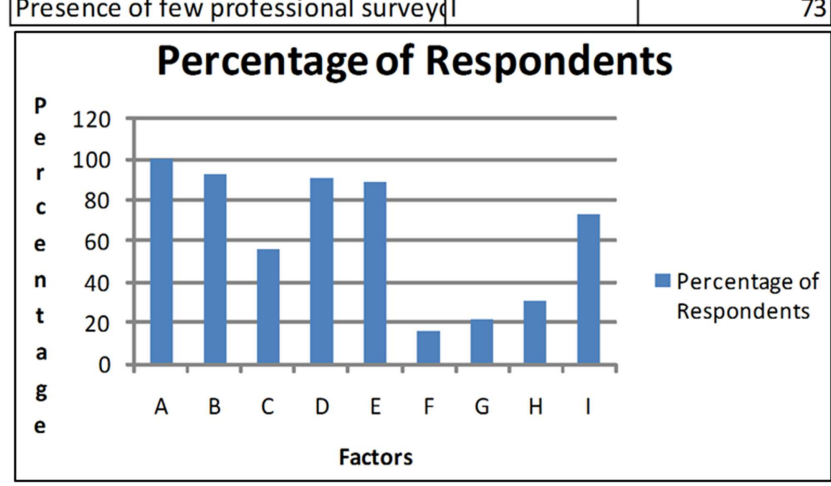

Figure 3. Factors associated to land conflicts.

\subsection{Conflict Resolution}

In response to conflict resolution, respondents argued to take great precaution during land use planning in order to reduce and or avoid land conflict. Different measures were suggested including but not limited to use of proper collected data for land use planning. Also more training should be conducted so as to have knowledge on surveying basically on data collection and use of accurate surveying instrument that will assist in accurate data collection (See figure 4 below).

On top of that, more emphasis were put in the use of competent surveyor during data collection as well as adherence to surveying professional practice especially during data collection and manipulation so as to get the accurate town planning drawing and or base map that will assist to reduce land conflict.

Factors for conflict Resolution

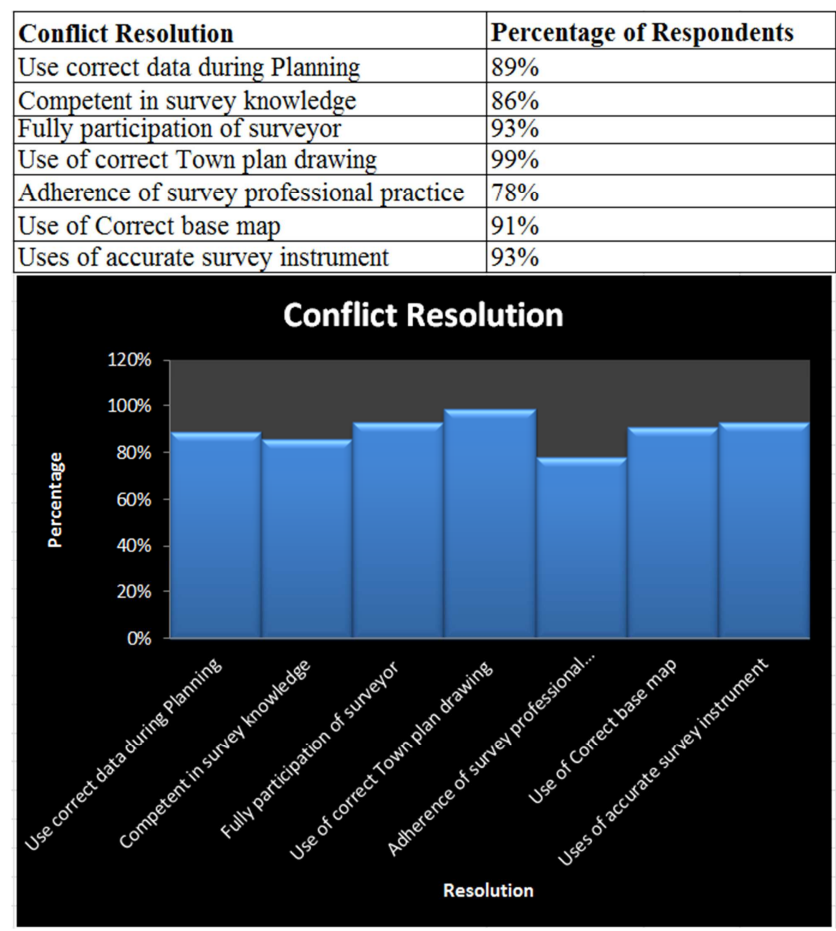

Figure 4. Factors for conflict resolution.

\section{Conclusion}

Land conflict has been noted to be an ever ending phenomenon in Mbeya rural area. Despite of the efforts done to reduce the land conflict, still the new one are happening. Despite of other factors, the improper application of surveying professional practice has to a great extent contributed to the rise of those conflict, Planners are encouraged either to acquire enough skills before data collection or competence in use of accurate surveying instruments or fully engaging the surveyor in data collection that will be used for land use planning. Conversely proper follow up of the surveying professional practice during all process may to great extents assist to reduce the land conflict.

\section{References}

[1] R. Ago (2000). A text book of surveying and leveling, North Market, Nai Sarak, Delhi.

[2] UN-HABITAT - UNITED NATIONS HUMAN SETTLEMENTS PROGRAM (ed.) (2012): Handling Land: Innovative Tools for Land Governance and Secure Tenure. United Nations Human Settlements Program/ International Institute of Rural Reconstruction (IIRR), Nairobi.

[3] SHIVJI, I. G. (1998): Not yet Democracy: Reforming Land Tenure in Tanzania. IIED (London)/HAKIARDHI/ Faculty of Law, University of Dar es Salaam, Dar es Salaam.

[4] Donge, J. K., \& Pherani, L. (1999). Law and Order as a Development Issue: Land Conflicts and the Creation of Social Order in Southern Malawi. The Journal of Development Studies, 36 (2), 48-70. 
[5] Andre, C., \& Plateau, J.-P. (1998). Land relations under unbearable stress: Rwanda caught in the Malthusian trap. Journal of Economic Behavior \& Organization, 34, 1-47.

[6] Deininger, Klaus. 2003. Land Policies for Growth and Poverty Reduction. Washington DC: World Bank.

[7] Engineering field Hand look, United Department of Agriculture, Natural resource conservation service, 210-VI-EFH, October, 2008.

[8] Baier, M. 1993. Village Level Development and Land Use
Planning, Part 2: Aberdare Workshop Report, Aberdare, Kenya, 15.2.-17.2.1993. Eschborn: GTZ, OE 425.

[9] Saafo Roba (2007). Land ownership and conflicts in Isiolo District, Kenya. Thesis for the degree of Master of Science in Development Studies, Norwegian University of Life Sciences, Norway.

[10] Bashiru Ally (2015). State and Market in urban land conflict. Thesis for the Doctor of philosophy, Department of political science, University of Dar es salaam, Dar es salaam, Tanzania. 